\title{
Aeromedical Evacuation of Patients with Contagious Infections
}

\author{
Brian T. Garibaldi, Nicholas G. Conger, \\ Mark R. Withers, Steven J. Hatfill, \\ Jose J. Gutierrez-Nunez, \\ and George W. Christopher
}

\section{Introduction}

The operational decision to evacuate patients with communicable diseases or those who are biologic warfare casualties is complicated by many factors, including the etiologic agent involved. Unlike nuclear or chemical casualties, patients with contagious infections may transmit disease after external decontamination. Further, theater medical facilities might be overwhelmed by a mass-casualty disaster after an epidemic or biologic warfare attack, necessitating rapid evacuation.

\footnotetext{
B. T. Garibaldi $(\bowtie)$

Department of Medicine and Physiology, Division of Pulmonary and Critical Care Medicine, Johns Hopkins Biocontainment Unit, Johns Hopkins University School of Medicine, Baltimore, MD, USA e-mail: bgariba1@jhmi.edu
}

N. G. Conger

Col, USAF, MC, Wright Patterson Air Force Base, Dayton, OH, USA

Division of Infectious Disease, Department of Internal Medicine, Wright State University School of Medicine, Dayton, OH, USA

\section{R. Withers}

COL, MC, USA (ret.), Office of Medical Support \&

Oversight, U.S. Army Research Institute of

Environmental Medicine, Natick, MA, USA
A comprehensive review of the aeromedical evacuation (AE) of patients with contagious infections would have to contain elements from several diverse disciplines. These would include disaster medicine, air transport medicine, critical care medicine, the ergonomics and aerobiology of aircraft interiors, infection control, international aviation law and diplomacy, and the operational requirements and constraints of the US Air Force (USAF) and other military and civilian services. We have limited the discussion in this chapter to the ecology of aircraft interiors, disease transmis-

\section{S. J. Hatfill}

Department of Clinical Research and Leadership, Department of Microbiology, Immunology, and Tropical Medicine, George Washington University Medical School, Washington,

DC, USA

\section{J. J. Gutierrez-Nunez}

Col, USAF, MC (ret.), University of Puerto Rico School of Medicine, Department of Medicine, San Juan Veterans Administration Medical Center, San Juan, PR, USA

G. W. Christopher

Col, USAF, MC (ret.), Medical Countermeasure Systems, Joint Program Executive Office for Chemical and Biological Defense, Fort Belvoir, VA, USA 
sion onboard aircraft, and highlights of the elements of military and civilian AE capabilities for patients with contagious infections or biologic warfare exposures. Unresolved issues will be identified with the goal of stimulating discussion and future research.

\section{Airframe as a Microbial Environment}

The engineering parameters of aircraft ventilation and pressurization are well known and tested extensively by aircraft manufacturers. While most studies of aircraft cabin air quality have focused on tobacco by-products and other chemical contaminants, few have addressed the ecology of airborne microbes. The few available studies of the aerobiology of aircraft interiors suggest that the modern aircraft interior is a less likely venue for disease transmission than most public places [1].

The risk of transmitting infections in modern aircraft under normal conditions is probably equal to, or lower than, the risks in other crowded enclosures. This is related to the excellent ventilation systems built into modem aircraft. However, when the ventilation system is not functioning (as is often the case prior to takeoff), the aircraft cabin environment increases the risk for transmission of airborne viruses such as measles and influenza.

\section{Ecology of Aircraft Cabin Air}

Air vented into most aircraft cabins is sterilized during pressurization. To maintain an internal cabin atmosphere equivalent to less than $8000 \mathrm{ft}$. above mean sea level while at altitude, pressurized air is extracted from the main jet engine compressor, where it has been subjected to both high temperature (more than $250{ }^{\circ} \mathrm{C}$ ) and pressure $(450 \mathrm{psi})$. The air is then cooled by a series of heat exchangers and vented into the cabin [2].

Microbial survival times are also altered by variations in relative humidity [3]. Because air at altitude has low relative humidity (10-15\%), the resultant compressed cabin air does also. Low humidity inhibits bacterial growth and stability but increases the survival and infectivity of cer- tain airborne viruses [4]. The influenza virus was found to survive longer in dry air (relative humidity $<50 \%$ ), while poliovirus survived longer in humid air (relative humidity $>50 \%$ ) [5].

\section{Ventilation: Air Distribution Systems and Airflow}

The three most important factors that determine the incidence of infections spread by airborne particles in an enclosed space are the susceptibility of those exposed, the duration of exposure, and the concentration of infectious droplets or droplet nuclei. The concentrations of droplets and droplet nuclei increase when the generation rate is high, when the static volume of enclosed air is small, and when fresh air ventilation is low. Ventilation of any enclosed space decreases the concentration of airborne organisms logarithmically, removing approximately two-thirds of the airborne droplets per air exchange [6].

The mechanism by which air is circulated through most large aircraft cabins depends on several factors. When on the ground, fans recirculate cooled or conditioned air throughout the cabin. When the engines are off, ventilation is provided in one of two ways: Either an auxiliary power unit runs the cabin ventilation system or preconditioned air is supplied by connecting a ground airconditioning unit to an air manifold. In some aircraft, no fresh air is taken in until pressurization is begun at altitude. However, older military transport aircraft (such as the C-130 Hercules) use pressurized air from the engines for ventilation whether on the ground or aloft. At altitude, compressed air enters continually while air is vented overboard via an outflow valve. First-generation jet airliners (e.g., Boeing 707s, Boeing 727s, DC-9s) and most military transports use $100 \%$ ambient (fresh) air for cabin supply [7].

The airflow design for most large aircraft is either circumperipheral or longitudinal. For both designs, conditioned air typically enters the cabin at standing head level. With the circumperipheral design, air circulates from aircraft skin to midcabin and then down and back to the vents near the skin at floor level on the same side. With the longitudinal design, air circulates from the air- 
craft skin in the midsection to outflow valves either fore or aft. The outflow valves are sometimes along the hull (two on the Boeing 707: one at the forward edge of the wings and the other near the tail) or elsewhere along the fuselage (below the right cockpit floor in the $\mathrm{C}-130$ ).

The type and direction of airflow during an $\mathrm{AE}$ flight have important implications for airborne spread of infection. In general, the circumperipheral mode is preferable to the longitudinal because it minimizes aircrew exposure to contaminated air. With the longitudinal design, the direction of airflow should be adjusted so that it is aftward by closing the forward outflow valves. In the C-9A Nightingale, cabin airflow is "top to bottom, front to back," and therefore, contagious patients are placed as far aft and as low as possible.

The airflow for the C-141 takes on special importance because of its history as the main strategic AE airframe for the US military. This aircraft also had a longitudinal airflow design, where the air enters both on the flight deck and the aft cargo compartment. Air then flows toward two outflow valves located above the aft pressure bulkhead [8]. Therefore, potentially infectious patients were placed as far aft and as high as possible. The ventilation patterns of the C-17 transport, which may assume some of the strategic AE missions in the future, remain to be characterized [9].

The risk of airborne infection to the flight crew is related to the flight deck airflow design. In many commercial airliners, such as the B-707, the flight crew is somewhat protected by the independent flight deck ventilation system. As noted previously, the C-141 flight crew is protected by the longitudinal system, where the air enters on the flight deck and flows aftward through the cabin. This is in contrast to the C-130, where the flight deck personnel may be at increased risk because all cabin air is drawn to the cockpit, where it is vented out [10].

Commercial airline cabin airflow has two important design features that may reduce respiratory droplet or airborne transmission. First, most cabins feature a flow design that is both circumperipheral and laminar, with air entering overhead, flowing down the sides, and exiting through vents above the floor. Second, they have relatively high air exchange rates, typically ranging from 15 to 20 exchanges per hour. This exceeds both the 12 air exchanges per hour that maintain air quality in modern office buildings and the 12 exchanges per hour recommended by the US Centers for Disease Control and Prevention (CDC) for the hospital isolation rooms of patients with active tuberculosis [11]. Unfortunately, the purging of air within the cabin may not always be uniform because of the laminar flow design. There may be decreased air circulation in fore and aft areas, resulting in stagnant zones; animal studies demonstrate that increased ventilation decreases airborne transmission in confined spaces $[12,13]$. It is important to remember that ventilation alone is not sufficient to prevent all transmission of airborne pathogens [14].

\section{High-Efficiency Particulate Air (HEPA) Filtration}

Jet engine efficiency is decreased by the extraction of compressor air for delivery to the cabin because this air is not available for additional thrust. To economize, commercial airliners use systems that partially recycle cabin air, rather than continuing to supply $100 \%$ fresh air from the engines. The fraction of recirculated air ranges from $24 \%$ to $66 \%$ [15]. The use of recirculated air may reduce air quality due to the recirculation of aerosolized contaminants. To counter this, most airlines have installed highefficiency particulate air (HEPA) filters in their recirculation systems. These are $99.7 \%$ effective for removing particles of $0.3 \mu(\mathrm{mu}) \mathrm{m}$ diameter or larger.

Although HEPA filters were originally installed for passenger comfort (e.g., for removing tobacco smoke), they also appear to reduce the risk of transmission of airborne pathogens $[16,17]$. The droplet nuclei carrying measles, varicella, and tuberculosis are typically $5 \mu(\mathrm{mu}) \mathrm{m}$ or less in diameter. A study commissioned by the US Department of Transportation to evaluate the levels of bacteria, fungi, carbon dioxide, ozone, and tobacco products in recirculated airliner cabin air found that microorganism concentrations did not reach levels considered hazardous to health [18]. 


\section{Microbial Aerosols in Aircraft}

In response to concerns generated by lethal viral hemorrhagic fevers, and a possible need to transport patients with these diseases by air, the ventilation and air-conditioning systems on pressurized, long-range transport aircraft were studied to evaluate the aerodynamics of aerosolized microorganisms [19]. The two aircraft evaluated were the Lockheed Martin C-130E Hercules (the aircraft used for most tactical AE) and the Boeing 707-347C. At the time, the aviation engineering knowledge of ventilation and air pressure changes on these aircraft was extensive. The movement of smoke particles was observed, and the dispersion of aerosolized spores of a nonpathogenic organism (Bacillus subtilis var. globigii) was assayed at multiple cabin sites under various pressure and ventilation conditions. Results of both smoke and spore studies suggested that the optimal location for placing a highly infections patient in the 707 would be the left rear of the cabin. When the aircraft was pressurized and the forward outflow valve was closed, contamination was largely restricted to the rear area, placing the flight crew at minimal risk if they stayed forward.

In view of its airflow design, it was no surprise that there was substantial drift of smoke from the cargo hold of the C-130 into the flight deck [19]. Approximately $3 \%$ of the spores released in the aft cabin reached the flight deck, probably enough to transmit infection over a prolonged flight if the organism had been infectious. The relative locations of the bleed valves and outflow valve would make plastic diaphragms impractical. One conclusion of the study was that high-containment isolators would be required to evacuate patients with potentially lethal contagious diseases in a C-130. These isolators would protect the flight crew and medical workers and allow refueling stops without alarming foreign governments, which might otherwise refuse international landing clearances (Fig. 20.1). These types of isolators are still used by non-US military forces for AE transport [20]. The US military and civilian transportation services have adopted a slightly different approach as will be discussed later.

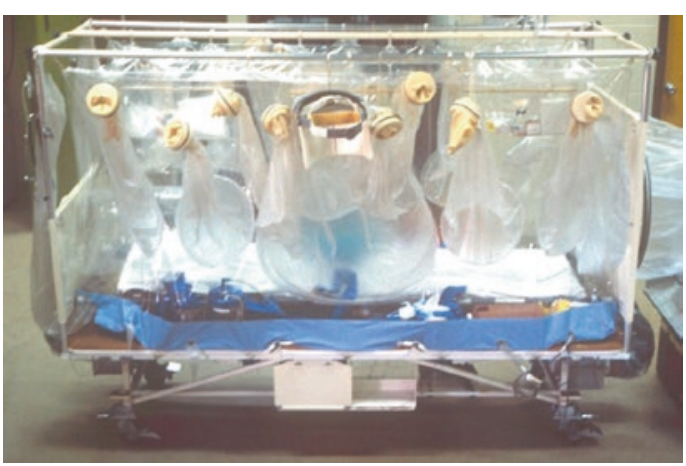

Fig. 20.1 The Vickers aircraft transport isolator (ATI) is designed for prolonged patient transportation and in-flight care. (Reprinted with permission from [59])

A second conclusion of the study was that such patients should only be transported in longrange jet aircraft with the air distribution characteristics similar to those of a Boeing 707 . However, significant air contamination occurs within the cabin while these aircraft taxi for takeoff with the recirculation fans functioning. To avoid this, the starboard engines should be operated with the forward outflow valve closed, thus ensuring rapid air exchanges within the cabin. Potentially infectious patients should be boarded through the rear passenger hatch and then placed in the left rear of the cabin facing aft. To protect the flight crew, patients and medical workers should venture no further forward than mid-cabin and flight crew no further aft than that same point.

These concepts were applied, without empiric validation, in 1974, when the aft area in a 707 was used to transport a patient with Lassa fever [21]. A 707 was selected because it was capable of a nonstop flight to Germany, obviating potential difficulties obtaining permission to refuel in a third country. This dedicated AE utilized extensive and unprecedented precautions to transport the patient (a German physician) from Lagos, Nigeria, to Hamburg. The patient was isolated in the rear of the cabin, and a "neutral zone" was created using two polyvinyl chloride partitions. The outflow valves were configured to create a longitudinal pressure gradient in the cabin so that airflow was from the forward to the aft section. Finally, to avoid microbial dissemination via 
recirculated air, the starboard engines were started to allow pressurization prior to boarding the patient through the aft door. After transporting the patient, the aircraft interior was fumigated with vaporized formalin for 6 hours, and there were no secondary cases.

Between 1987 and 1994, the air was sampled for microorganisms on 36 domestic and international flights, including small and large jet airliners and turboprop commuter aircraft [22]. It was assumed that all microbial contamination originated from passengers and crew because the air taken in from the engines was presumably sterile. It was also assumed that lower levels of microbial air contamination would correlate with a lower risk of disease transmission, although this has not been validated clinically. Control samples were taken at urban locations such as buses, malls, streets, and airports. Microorganisms were quantified by counting colony-forming units (CFUs) after 72 hours incubation, but no attempt was made to identify the organisms.

This study found no significant differences between air at sea level and higher sites nor between coach, business, first-class, or galley sections [22]. The highest counts came from samples taken near outflow vents, about 1 foot above floor level. Interestingly, the microbial air contamination found during flight was significantly lower than that found in cities, buses, and public buildings. Decreased passenger movement (e.g., during sleep) correlated with lower numbers of $\mathrm{CFU}$. The authors concluded that "the small number of microorganisms found in US airliner cabin environments does not contribute to the risk of disease transmission among passengers." [22]

\section{Disinfection of Aircraft}

Disinfection of the aircraft is an important element to consider in the $\mathrm{AE}$ of infectious disease patients. The World Health Organization (WHO) specifies basic advice on hygiene and sanitation [23] but does not provide details on standard operating procedures (SOPs) or disinfectants to use. In 2014, the Lufthansa group implemented and shared SOPs for the safe decontamination of commercial aircraft, taking into consideration passenger and crew safety, aircraft operability, aircraft instillations, and aircraft certifications. Lufthansa Technik Central Laboratories studied the effects of several alcohol-based, formaldehyde-based, and oxygen-releasing disinfectants on aircraft materials including glass, metal, electric conduits, synthetics, and seat covers to determine the safe application and techniques to be used on their airline fleet [24].

\section{Survey of Infectious Disease Transmission in Aircraft}

The risk of transmitting infections in aircraft has probably been exaggerated [25]. Most reports of disease transmission onboard aircraft describe foodborne outbreaks on commercial airliners [26], a discrete area of relevance to AE. The following is a brief summary of the transmission of several common pathogens.

\section{Tuberculosis}

Tuberculosis is an obvious concern aboard AE aircraft because it is a common and serious disease usually spread via airborne transmission, especially in confined spaces [27]. Three conclusions about the risk of tuberculosis spread can be drawn from the limited number of published retrospective cohort studies of tuberculosis exposures aboard aircraft. First, the risk of tuberculosis transmission aboard an aircraft is apparently no greater than in other confined spaces, with reported conversion rates of $2-4 \%$ $[28,29]$. Second, the duration of exposure appears to be important, with several studies reporting no tuberculosis transmission after exposure to an infectious patient after flights less than 9 hours in duration [30, 31]. Finally, the risk of conversion appears much greater for those seated within two rows of an infectious passenger on airlines with a laminar air flow system [32]. Based on this information, the CDC recommended that "those known to be 
infectious travel by private transportation rather than by commercial aircraft" [28].

The CDC has also suggested three criteria to determine which passengers and flight crew members should be notified of the possibility of tuberculosis exposure [28]. First, the person with tuberculosis was infectious at the time of the flight. Infectiousness can be assumed if the person was symptomatic with acid-fast bacilli (AFB) smear-positive, cavitary pulmonary, or laryngeal tuberculosis or has transmitted the disease to household or other close contacts. Second, the exposure was prolonged (i.e., duration of flight exceeded 8 hours). Finally, passengers and flight crew who were at greatest risk for exposure based on proximity to the infectious passenger should be given priority for notification. Routine tuberculosis screening for airline crew members has not been recommended as an occupational health measure.

\section{Influenza}

Air travel has significantly altered the epidemiology of influenza. Since the 1950s, it has become clear that influenza pandemics have followed major air transportation routes. Influenza has also been transmitted during flight. Because of confinement in a closed space associated with flight, these cases most likely constitute common-source, single-exposure outbreaks rather than the usual linear "personto-person-to-person" epidemics.

Based on published reports, several conclusions can be drawn. First, prolonged ground delays may increase the risk, especially if the air ventilation system is not functioning. In one such report, $72 \%$ of the passengers became ill and there was a strong association of the rate of illness with the duration of exposure to the ill passenger [33]. Thus, a second conclusion is that the length of exposure is important. But, in contrast to tuberculosis, even patients exposed for less than 1 hour appear to be at significant risk. Third, the attack rate of influenza aboard a wellventilated airliner appears to be higher than the general community attack rate during epidemics
(10-20\%) but less than the rate for boarding schools or nursing homes (>50\%) [34].

A major problem with influenza is that individuals do not show signs of infection until several days after they have become infected. During this time, the influenza virus multiplies in the cells lining the upper respiratory tract and sheds into the environment around the infected individual. The infected person may feel slightly unwell but nowhere ill enough to miss work or travel, and they can transmit the virus to others around them. Individuals infected with influenza A virus are usually infectious for at least 1-2 days before the onset of symptoms. After several days of infection, individuals develop fever and the other classical symptoms of influenza, and they remain infectious up to 5-7 days after becoming ill [35]. Infants and immunocompromised individuals can shed influenza virus particles for up to 21 days.

Respiratory protection alone is not fully protective against influenza virus exposure, infection, and severe disease because the human eye is a target for entry of some influenza A virus strains into the human respiratory tract. Both the cornea and the conjunctival epithelial cells contain the sialic acid molecules that serve as the receptors for the H protein of the influenza virus [36]. When the human eye contacts a suspended small-particle influenza virus-laden aerosol from an infected patient's cough or sneeze, surface tension can draw the viral particles to the epithelial cells onto the ocular surface where they adhere. Once adherent, the nasolacrimal drainage system can drain attached viruses from the eye surface through the tear ducts into the nasopharynx within 30 minutes.

\section{Measles}

Measles is one of the most contagious infectious diseases, with an attack rate of about $80 \%$ among susceptible, casual contacts. Spread by droplet nuclei, virions can survive in the air for several hours. During the early 1980s, more than 500 measles cases per year were either imported to the United States or acquired from imported cases. Most of the imported cases 
were associated with air travel, and several secondary cases were acquired during flight [37].

An important aspect of measles transmission is that it may occur before the patient becomes symptomatic, a day or two before the end of the incubation period. In one report, eight passengers became infected on a single flight even though no ill or coughing passengers were observed during the flight [38].

\section{Smallpox}

During the Intensified Smallpox Eradication Program (1967-1980), concern was extremely high that smallpox would be reintroduced to Europe or the United States from endemic areas by air travel. Consequently, smallpox vaccinations and boosters were recommended for national and international flying personnel [39]. From 1959 to 1973, 27 of the 29 known cases of smallpox imported to Europe were associated with air travel. None were acquired during flight, as all case patients traveled during the incubation period [40]. There is one case of potential infection during air travel, but it is unclear whether transmission occurred in the air or in a terminal [41].

\section{Viral Hemorrhagic Fevers}

Viral hemorrhagic fevers (VHFs) are caused by a taxonomically diverse group of RNA viruses and feature a febrile syndrome with severe vascular abnormalities. In general, they are associated with high rates of morbidity and mortality. With the exception of Lassa fever, little is known about their transmissibility during air transport.

Prior to the Ebola outbreak of 2014-2015, much of the attention paid to AE for viral hemorrhagic fevers focused on Lassa fever. The mortality and communicability of Lassa fever had engendered a cautious approach to these patients in the West from both the medical and aeromedical communities. As reported above, an infected patient transported from Lagos to Germany was the sole patient on a C-141, and the patient together with the aeromedical crew were quarantined from the flight crew [22]. Perhaps the most unusual AE in history occurred when a CDC worker with Lassa fever and his wife were transported from Sierra Leone to the United States on a C-141 [42]. For lack of an isolation chamber, they were both sealed for the duration of the flight in an Apollo space capsule that had been flown from a US military warehouse in Germany.

Fortunately, the risk of transmission of Lassa fever, both on the ground and during commercial flight, appears to be low. There have been two reports of inadvertent exposure of large numbers of susceptible individuals to patients with Lassa fever in Western hospitals without evidence of secondary transmission [43, 44]. On at least four occasions, passengers with Lassa fever have traveled on commercial overseas flights without a single secondary case occurring [42-45]. This suggests that the apparently high transmission rate of Lassa fever in West African hospitals may be due to local infection control practices [43, 45].

Based on these reassuring reports, it was suggested that Lassa fever patients could be safely transported by AE using simple barrier infection control techniques [43, 46]. However, the WHO strongly discourages the transport of Lassa fever patients from endemic to non-endemic areas, stating that this should be undertaken only in exceptional circumstances and should be accomplished using special precautions including highcontainment isolators [47].

The Ebola outbreak of 2014-2015 provided the largest experience for the $\mathrm{AE}$ of patients with viral hemorrhagic fevers. A number of healthcare workers who acquired the infection while caring for patients in West Africa were transported to healthcare facilities in developed countries for treatment. While several of these patients were transported by military services [20], the majority of patients were transported using civilian aircraft that were contracted to provide AE services by government agencies [48]. Phoenix Air, a commercial transport service based in the United States, transported 21 confirmed Ebola patients and 19 high-risk exposures [49]. In all cases, AE providers used special precautions and some 
form of high-containment isolation system during transport. There were no reported cases of Ebola transmission to the healthcare workers or personnel of these AE flights.

\section{Severe Acute Respiratory Syndrome (SARS)}

The international spread of respiratory disease due to the severe acute respiratory syndrome (SARS) coronavirus was accelerated by longdistance travel of symptomatic and incubating patients from Hong Kong to Vietnam, Canada, the United States, and Europe [50]. The risk of transmission during air travel was underscored by a cluster of 22 cases acquired during a flight from Hong Kong to Beijing, traced to a 73-year-old superspreader. However, another flight carrying four symptomatic patients led to only one secondary case, and a flight carrying a patient during incubation resulted in no additional cases [51]. Surveillance of passengers in seven flights carrying symptomatic SARS patients to the United States identified no transmission events [52]. An analysis of SARS transmission during commercial flights carrying symptomatic SARS patients to Singapore disclosed transmission in only one of three flights, for an attack rate of less than $1 \%$. The authors concluded that SARS was less communicable than influenza during air travel [53].

\section{In-Flight Preventive Measures}

The most effective method to minimize disease transmission is to defer $\mathrm{AE}$ of infectious patients until after the period of communicability. Unfortunately, there are many situations in which infectious patients must be evacuated, and $\mathrm{AE}$ planners must be ready to respond.

Early diagnosis of communicable diseases is the key to prevent transmission. Only then can disease-specific, transmission-based precautions be promptly implemented. Attempts are currently underway to develop portable, rapid diagnostic tests, such as enzyme-linked immunosorbent assays and genetic typing, which can be used in the field. In the presence of a biologic warfare threat, patients will be screened for incubating infections (e.g., smallpox) prior to being transported for other indications to minimize the risks of evacuation-related epidemics.

When a casualty is determined to be infectious, the most obvious preventive measure would be to defer AE until after the communicable period. However, such casualties might need evacuation sooner for tactical or other reasons. The use of restricted flights for transportation of cohorts with specific communicable diseases would obviate the risk of patient-to-patient transmission but offer little protection to either the aeromedical or flight crews.

When transporting any infectious patient, standard infection control practices are essential. Additional transmission-based precautions are necessary for certain infections. CDC guidelines mandate the use of surgical masks for diseases transmitted by droplets (e.g., influenza) and fittested HEPA-filtered masks for diseases transmitted by droplet nuclei (e.g., tuberculosis) in hospitals. These guidelines have been adapted for use in aircraft [54]. The USAF is currently developing a comprehensive regulation on infection control on aircraft.

Judicious patient placement should be used to minimize the transmission of disease by respiratory droplet or droplet nuclei based on the ventilation characteristics of the specific aircraft. For example, infectious patients are placed as far aft and as low as possible in the C-9A but as far aft and as high as possible in a C-141 [8]. The ventilation pattern of the $\mathrm{C}-17$ transport remains to be characterized [9].

The C-130 is potentially the most problematic from an infectious disease perspective because cabin air is vented out through the cockpit [10]. In high-risk situations, the flow of cabin air can be reversed aftward by opening the safety valve located in the cargo door [55]. Unfortunately, the aircraft cannot be pressurized in this configuration, necessitating an altitude restriction. As an additional protective measure, the recirculation fan in the cargo compartment can be turned off to prevent recirculation of droplet nuclei. 
In a commercial airliner, HEPA filtration confers some level of protection. This may become an important factor in a large conflict, where Boeing 767 passenger aircraft might be used to transport a large number of potentially infectious ambulatory patients. However, this is unlikely to be a major benefit to AE, since the Civil Reserve Air Fleet (CRAF) program, wherein Boeing 767s could be converted into air ambulances, no longer exists (see Chap. 8).

Another possible approach is airflow compartmentalization, where plastic partitions, neutral zones, contaminated zones, and pressure gradients are used in an attempt to minimize crosscontamination [22]. Although this approach might be considered in exceptional cases, no protocols for these measures currently exist for use in US AE aircraft, primarily because they have yet to be proven effective in practice.

\section{High-Containment Isolation Systems}

High-containment isolation systems can be used for transporting a limited number of patients with highly contagious, potentially lethal diseases. Unfortunately, these isolators are limited in both number and capability and require specially trained teams of medical personnel. These isolators are necessary for the implementation of the extremely strict CDC infection control guidelines for the care and $\mathrm{AE}$ of patients with infections such as arenavirus, filovirus, and bunyavirus hemorrhagic fevers [37, 56-59]. They have been deployed for evacuating patients with suspected or proven VHF and active pulmonary tuberculosis [20, 48, 60, 61]. Although valuable for evacuating limited numbers of patients, they would not be suitable for evacuating mass casualties. A number of isolators are currently available. Table 20.1 compares and contrasts the capabilities of current high-containment isolation systems.

\section{Air Transportable Isolator (ATI)}

The air transportable isolator (ATI) is the oldest isolator that is currently in use (Fig. 20.1) [59]. Phillip Trexler developed the first model in 1975 to provide care for patients with severe immunodeficiency based on technology that was used for gnotobiotic animal research [62]. Two years later he developed a negative pressure version of the ATI to isolate patients with high consequence pathogens [63].

The ATI is a transparent polyvinyl chloride envelope suspended on a portable frame $(221 \mathrm{~cm}$ $\times 69 \mathrm{~cm} \times 86 \mathrm{~cm}$; weight $112 \mathrm{~kg}$ ). The envelope incorporates gloved sleeves, "half-suits," and transfer and docking ports for patient ingress and egress and for introducing supplies. Negative air pressure is maintained by an electrical air handling system powered by either the aircraft electrical system or rechargeable portable batteries. HEPA filters are utilized on both the air intakes and exhaust.

Challenge studies demonstrated that the system contained aerosolized bacteriophage during isobaric and hypobaric conditions and could withstand rapid decompression. The isolator can be equipped with portable oxygen tanks, cardiac monitors, pulse oximeters, intravenous fluids and tubing, medications, sphygmomanometers, and defibrillators. To minimize the risk of puncturing the isolator, phlebotomy is minimized, and a needleless intravenous (IV) system can be used. Sharp instruments are avoided.

Communication between patients and caregivers is limited by poor sound transmission through the envelope, noise generated by the air exchange

Table 20.1 Comparison of current high-containment isolation systems

\begin{tabular}{l|l|l|l|l}
\hline & ATI & ABCS & CBCS & TIS \\
\hline Max no. of patients & 1 & 1 & 4 & 8 \\
\hline Direct patient care & Limited & Yes & Yes & Yes \\
\hline Aircraft & C-17 & Gulfstream G-III & Modified Boeing 767 & C-17, C-130 \\
\hline
\end{tabular}

$A T I$ air transportable isolator, $A B C S$ aeromedical biological containment system, $C B C S$ containerized biocontainment system, TIS transportation isolation system 
system, and background aircraft noise but can be improved with handheld two-way radios. Physical examinations are difficult to conduct through the gloved sleeves. Suction capabilities are limited, and mechanical ventilation is not feasible.

Contraindications to transport in the Vickers ATI included acute respiratory failure or the presence of gas trapped within closed body cavities that may pressurize at high altitudes (e.g., pneumothorax, ileus, or bowel obstruction) $[64,65]$.

The US Army Medical Research Institute of Infectious Diseases (USAMRIID) used the ATI as part of its Aeromedical Isolation Team until 2007 [66]. The ATI was used in the AE of two Ebola patients to the United Kingdom by the Royal Air Force (RAF) during the 2014-2015 Ebola outbreak. Prior to the Ebola outbreak, the RAF had maintained three ATIs and had used them on only four occasions. During the outbreak, the RAF increased their capacity to 28 isolators.

\section{Aeromedical Biological Containment System (ABCS)}

In 2005, Phoenix Air was asked by the CDC to help develop a transport system for patients with SARS. Manufactured by Production Products in St. Louis, the result was the Aeromedical Biological Containment System (ABCS) (Fig. 20.2). While the ABCS was never used to transport SARS patients, the US Department of State enlisted Phoenix Air to use the ABCS for AE of two US medical personnel who contracted Ebola in West Africa in 2014.

Providers are required to wear personal protective equipment in order to enter the ACBS containment area and provide care. This is in contrast to the ATI, which contains the patient and allows providers external access. The ABCS uses a metal exoskeleton to support an internal plastic liner that creates an airtight isolation chamber. The patient is placed in the chamber, and an anteroom

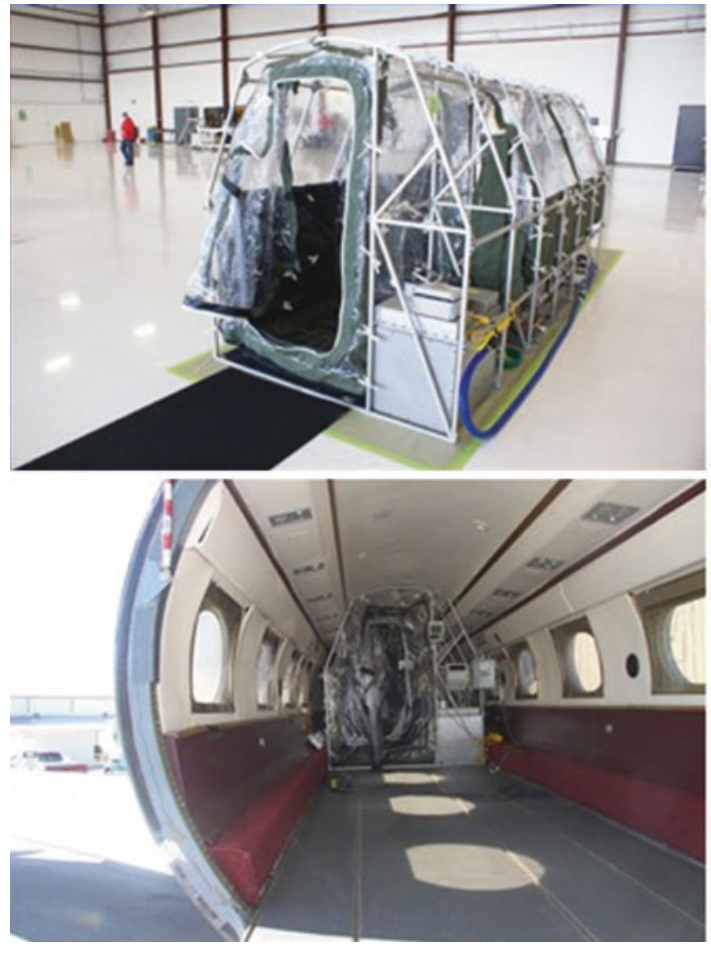

Fig. 20.2 The Aeromedical Biological Containment System (ABCS) was used by Phoenix Air to transport Ebola patients to the United States and Europe during the

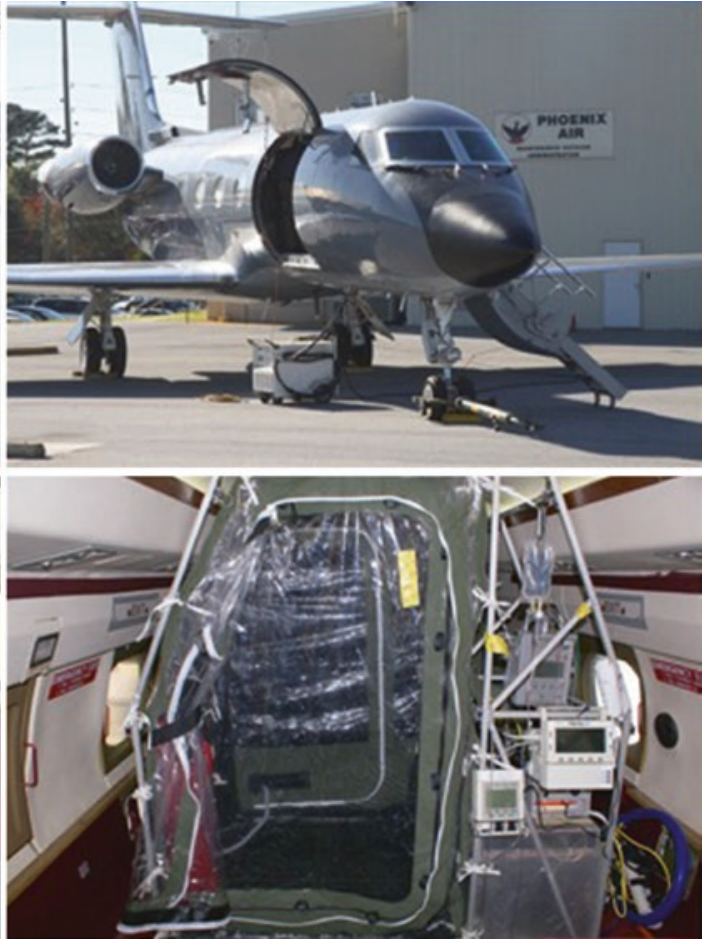

2014-2015 outbreak on a modified Gulfstream G-III. (Photos courtesy of Michael Fleuckiger from Phoenix Air) 
allows healthcare personnel to don personal protective equipment (PPE) before entering. The chamber is maintained at negative pressure using an air pump, and both the air intake and exhaust are HEPA filtered. Exhaust air is pumped through a valve in the aircraft fuselage. The entire chamber is placed inside a modified Gulfstream G-III aircraft, in which the direction of cabin air has been reversed to flow fore to aft. The ABCS was used for 38 transports during the Ebola outbreak of 2014-2015 [49, 67].

\section{Containerized Biocontainment System (CBCS)}

Recognizing that the ABCS is only able to transport one patient at a time, Phoenix Air worked with the Paul G. Allen Foundation, the US Department of State, and MRIGlobal to create the Containerized Biocontainment System
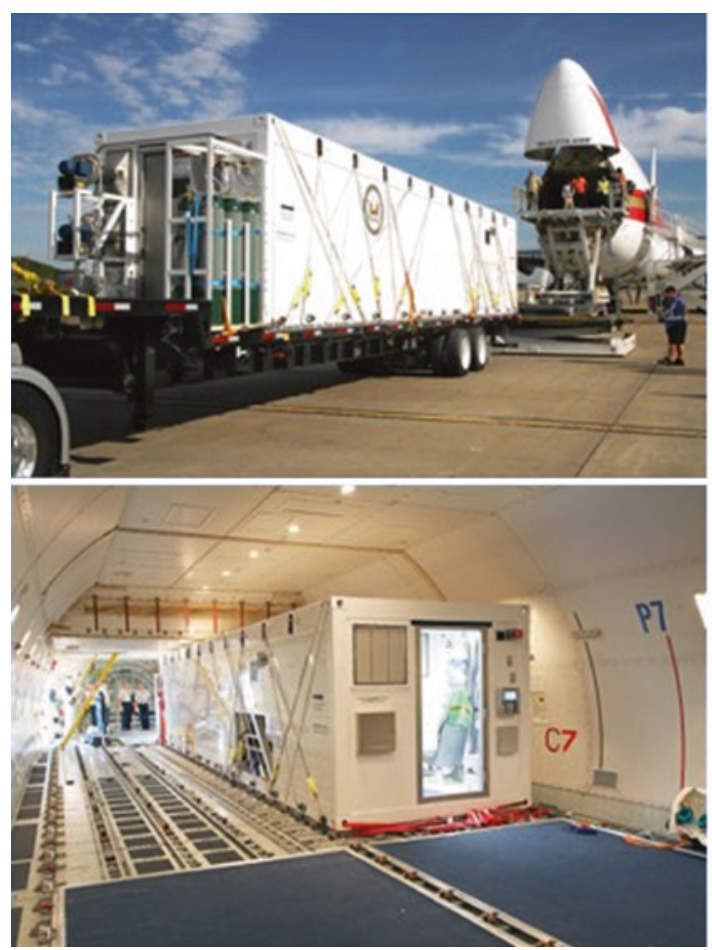

Fig. 20.3 The Containerized Biocontainment System (CBCS) was developed to transport up to four patients with highly infectious diseases on a modified 747 or mili-

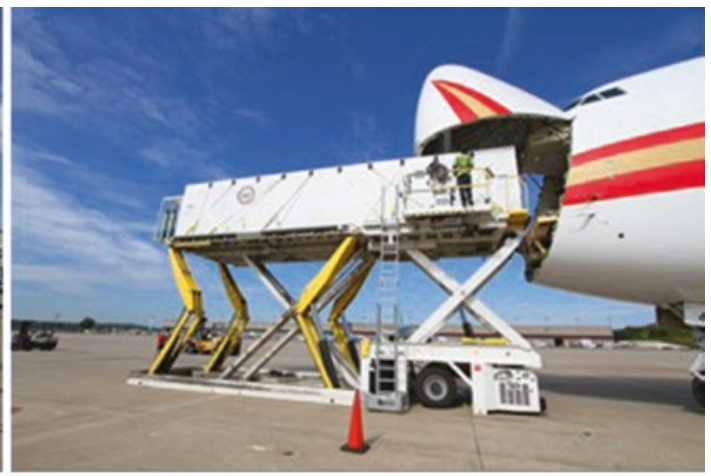

(CBCS) (Fig. 20.3). The CBCS is a 44-foot cargo container that can hold up to four patients who all have the same highly infectious disease. The container has a medical staff room, an anteroom, and a patient treatment area. The entire container is maintained under negative pressure, and air intake and exhaust are HEPA filtered. Two containers can fit in a modified Boeing 747 or a military cargo transport [49, 68]. While the CBCS has not been used to transport a confirmed patient, it has been used in three large-scale drills, including the international transport of 11 standardized patients from Sierra Leone to the United States as part of Operation Tranquil Shift in 2017 [69].

\section{Transportation Isolation System (TIS)}

In response to the Ebola outbreak, the USAF worked with Production Products to develop

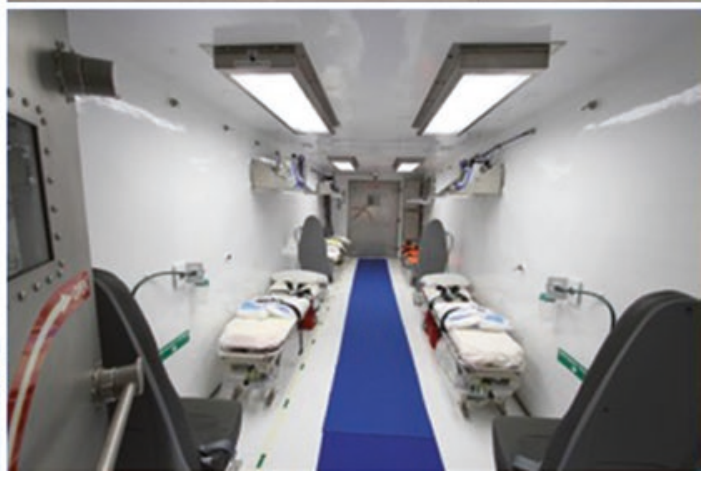

tary cargo plane. (Photos courtesy of Michael Fleuckiger from Phoenix Air) 
the Transportation Isolation System (TIS). The TIS is similar in design to the ABCS in that it has an exoskeleton that is draped with plastic sheeting. The TIS is modular and can combine two patient care pods, each with the capacity to hold four patients. The entire unit is under negative pressure and has an anteroom for providers to don PPE. All intake and exhaust air is HEPA filtered. The TIS can be loaded onto a C-17 or C-130 Super Hercules. In total, the Air Force commissioned 25 TIS units during the Ebola outbreak [70]. While it has never been used for confirmed case transport, the TIS has been successfully deployed in several military exercises (Fig. 20.4).

\section{Aircrew Chemical/Biological Protective Systems}

\section{Aircrew Eye/Respiratory Protection (AERP) System}

The USAF has anticipated the possible future challenge of operating in a chemically contaminated environment by introducing the Aircrew Eye/Respiratory Protection (AERP) system, which is in essence a gasmask for aviators (Fig. 20.5) [71]. Transport aircraft have been equipped with the AERP system, and these could be used to protect aeromedical crew members from infection. The system consists of a mask-
Fig. 20.4 The USAF Transportation Isolation System (TIS) is a modular system that can transport up to eight patients with highly infectious diseases. AE crew members wearing personal protective equipment are exiting the TIS during Exercise Mobility Solace at Joint Base Andrews,

Maryland (US Air Force Photo/Airman Megan Munoz)

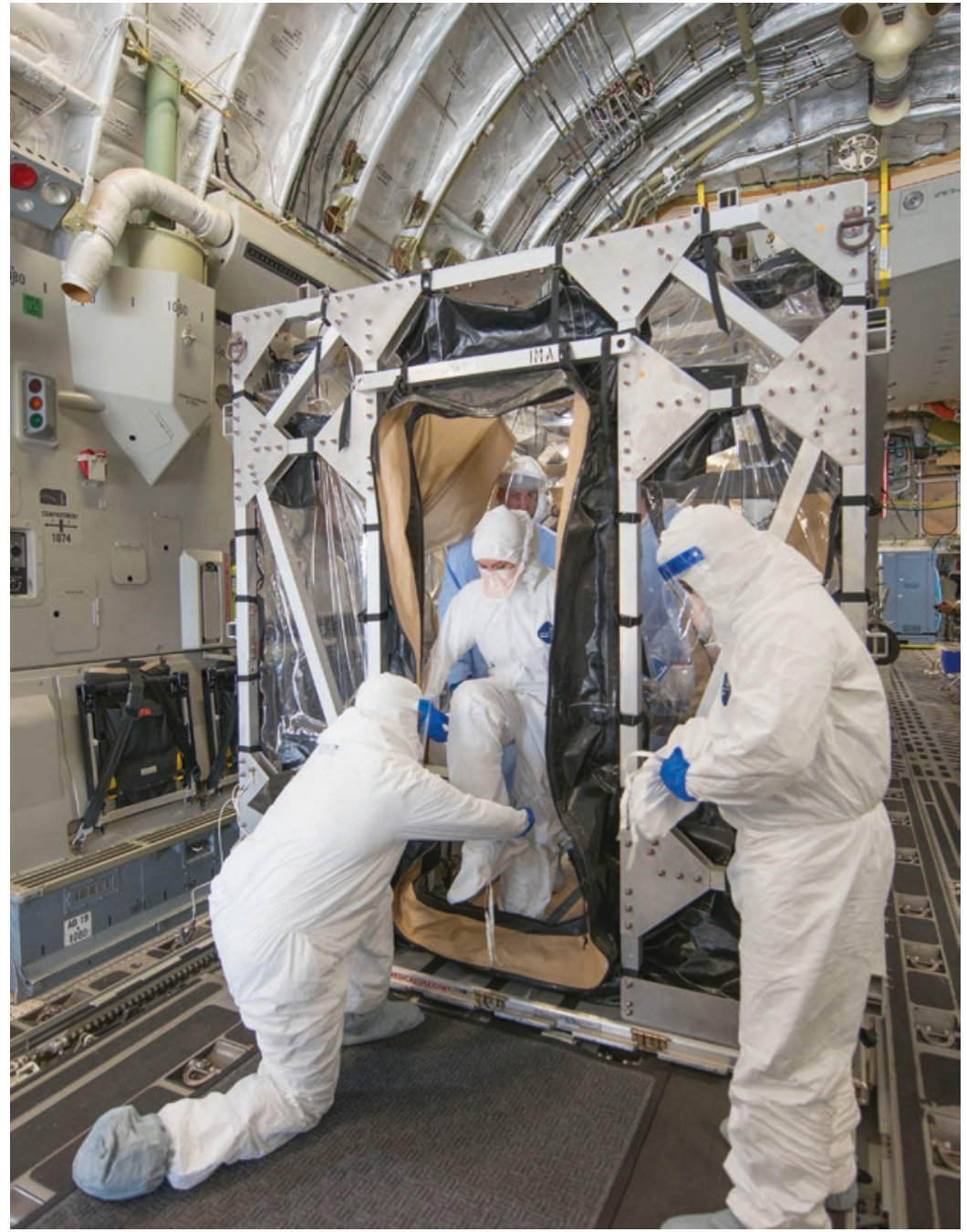


Fig. 20.5 An aircrew member wears the XM69 Aircrew Chemical, Biological, Radiological, and Nuclear (CBRN) Defense system while standing next to a mannequin wearing the legacy US Air Force Aircrew Eye/Respiratory Protection (AERP). (US Air Force photo/Senior Airman Zachary Cacicia)

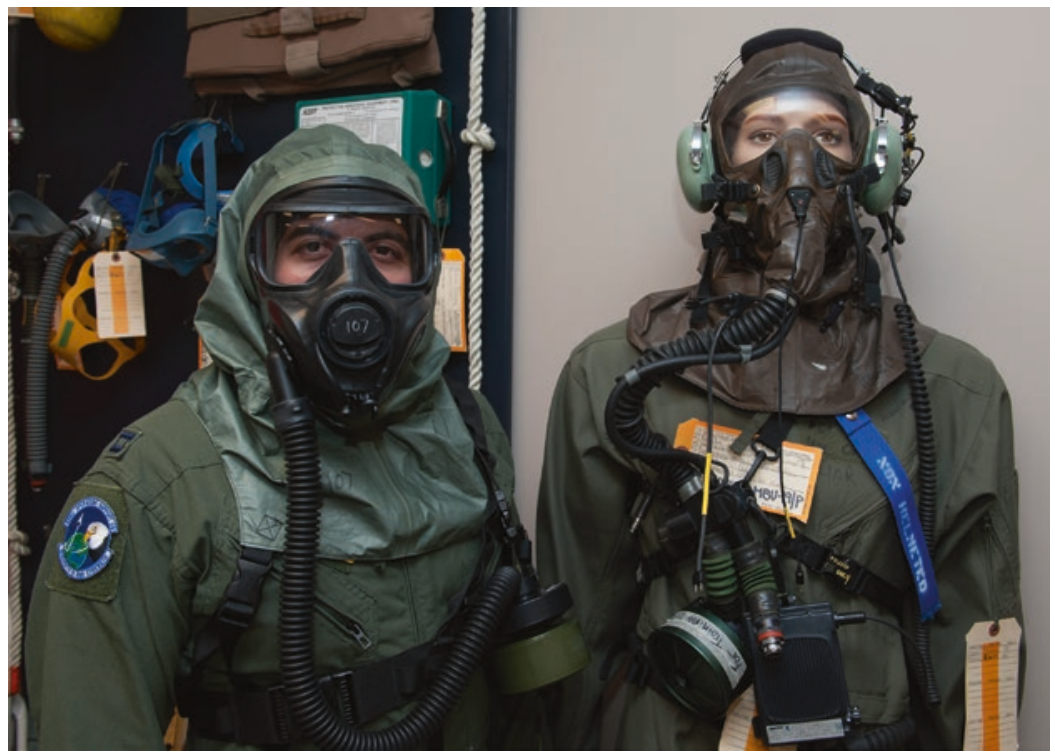

hood assembly, a blower, and an intercommunication unit. The C-9A, which is no longer in service with the USAF, could be configured to carry eight AERP stations located throughout the aircraft. There are fewer such stations on the C-17, C-130, and C-141 aircraft.

During flight, regulated aircraft oxygen is passed through the filter/manifold subassembly to the mask for breathing, while filtered ambient air is used to provide visor defogging. On the ground, filtered ambient air is used. The AERP blower is powered by the aircraft electrical system or by batteries. The AERP system is available in most aircraft used for military AE, and all aeromedical crew members routinely train for its use during emergencies [72].

\section{Aircrew Chemical, Biological, Radiological, and Nuclear (CBRN) Defense System}

The newest USAF chemical biological protective system, the XM69 Aircrew Chemical, Biological, Radiological, and Nuclear (CBRN) Defense system, was developed in conjunction with the Department of Defense [73]. This system is to be utilized by aviators from all four US military branches.
The system is designed to be more comfortable and with decreased acquisition and sustainment costs. It is currently undergoing testing and evaluation to establish reliability and determine maintainability. The goal is to replace all AERPs with the XM69 system for all aircrew members, regardless of the airframe they fly.

\section{US Military Policies for Evacuating Contagious Patients and Biologic Warfare Casualties}

\section{Historical Review}

Aeromedical evacuation of US service members with contagious diseases has been routinely undertaken since the establishment of a military AE service in 1942. During World War II, C-46 Commandos, C-47 Skytrains, and C-54 Skymasters were reconfigured to carry litters after unloading military cargo, becoming air ambulances on their return flights to the United States [74].

Air transportation was soon determined to be the most desirable method of evacuation for all but the sickest of active tuberculosis patients [75]. Those with large tension cavities or therapeutic pneumothoraces could not be moved by 
air because intrapleural gas volume would double as these unpressurized aircraft ascended from sea level to $18,000 \mathrm{ft}$. In most cases, patients were held at hospitals of embarkation until a sufficient number accumulated to fill a dedicated flight of tuberculosis patients. A trained nurse was usually present, and strict "sanitary precautions" and "proper isolation" were practiced. However, the aeromedical personnel were not screened with tuberculosis skin tests [75]. Consequently, the number of new tuberculosis infections occurring during these early air evacuations is unknown.

In 1954, the first aircraft specifically designed and dedicated to routine air medical transport, the C-131A Samaritan, entered service. It could carry specialized medical equipment and was capable of cabin pressurization. In 1961, the Boeing 707 jet was modified by the military to become the C-135 Stratolifter and soon became the mainstay of the first permanent intercontinental airlift system. Meanwhile, the C-130 Hercules began to see use for tactical AE. In 1965, the C-141 Starlifter began to replace the $\mathrm{C}-135$ for strategic (i.e., overseas) AE. This jet aircraft represented a quantum increase in patient load, range, speed, and control of cabin environment.

During the Vietnam War, helicopters moved wounded from the battlefield to medical treatment facilities in rear areas. From there, C-130 Hercules, C-123 Providers, and C-7 Caribous moved them to rear airfields, where C-141 Starlifters embarked on intercontinental routes. $\mathrm{AE}$ became so efficient that evacuees were sometimes received in a continental US medical facility within 24 hours of wounding. Large-scale actions in Vietnam in 1968 demonstrated the ability of the AE system to successfully respond to periodic surges of patients.

In 1968, the USAF received its first C-9A Nightingale, a military version of the McDonnell Douglas DC-9 specifically designed and dedicated for AE. New features included a special area for patient isolation and intensive care, a hydraulic ramp to facilitate enplaning of litter patients, integrated electrical and suction outlets, and medical supply and storage equipment cabinets. The C-9A fleet was decommissioned in 2005. The USAF currently conducts aeromedical evacuation by adapting a variety of aircraft including the $\mathrm{C}$ 130 and $\mathrm{C}-17$.

The cornerstone of the current infection control program is adherence to the CDC guidelines for infection control. Any infections thought to have been acquired during $\mathrm{AE}$ are to be reported to the Air Mobility Command Surgeon's Office, Scott Air Force Base (AFB), Illinois. To date, no cases have been reported.

\section{Biologic Warfare Casualties}

Military doctrine regarding all aspects of the medical management of biologic warfare casualties, including AE, is currently under development. Much of the existing joint and USAF doctrine relevant for the $\mathrm{AE}$ of nuclear, biologic, and chemical casualties does not clearly differentiate between these three groups. Clearly, there are significant differences among the diseases produced by these three weapons of mass destruction.

The USAF Surgeon General has developed interim guidelines for the AE of biologic warfare casualties. These guidelines are based on rational infection control procedures recommended for the infectious diseases caused by potential agents. Before these interim guidelines can be implemented locally, they must be approved by the appropriate theater commander-in-chief (a nonmedical general officer) and theater surgeon.

A key element of any successful approach to the treatment and transportation of biologic warfare casualties is early and rapid identification of exposure, clinical diagnosis, and laboratory confirmation using field diagnostic tests [76]. To meet this need, the USAF is preparing to deploy multiple specialized teams and has developed a portable device that can quickly 
identify organisms by genetic typing. It is now projected that these teams will interface with the AE system as integral components of aeromedical staging facilities.

\section{International Legal and Regulatory Aspects}

In the 1970s, widely publicized outbreaks of Lassa and Ebola fevers in Africa spurred considerable interest among airline officials and public health authorities. In retrospect, inappropriate and unnecessary measures were instituted at airports in many countries to minimize the risk of disease importation. In commenting upon what he considered a deplorable state of affairs, Michel Perin of Air France's Central Medical Service wrote:

\begin{abstract}
Most airline companies refuse to admit aboard passengers known, or believed, to have contagious diseases. Such stringency can scarcely be justified by reference to laws or regulations, whether national or international. It introduces the risk of arbitrary, mistaken, or prejudiced conduct. It does not seem logical because airlines learn about only a small fraction of the contagious persons who travel, and public health is much more greatly endangered by unknown infectious persons. Normal hygienic conditions aboard planes usually suppress the risk of contagion of most diseases. The possibility of refusing admission should be given to airlines in certain cases, according to their doctor's appreciation. [77]
\end{abstract}

Perin suggested that exclusionary rules should be applied "only against someone who refuses to comply, or seems incapable of complying, with the conditions intended to make him harmless, or against someone who has such an infectious disease that it would be impossible to make him harmless to others" [77].

Insight into how the international community reacts to even rumors of highly contagious diseases among airline passengers can be gleaned from events of August and September 1994. An epidemic of plague in the Indian city of Surat resulted in panic and chaos. Many of the inhabitants, including most physicians, evacuated themselves from the city. Panic spread rapidly to commercial air carriers, with all but two international airlines canceling flights to India. Indians deplaning at airports around the world were evaluated for signs of plague, and, in Canada, airport workers donned gloves and masks [78]. Eleven febrile Indian passengers were promptly quarantined when they deplaned in New York City. None had plague, but four were found to have malaria, one had dengue fever, and one had typhoid fever [79].

The most recent experience with Ebola in 2014-2015 further highlighted the potential for panic in response to a highly infectious disease. After the start of the outbreak, several US lawmakers called for a complete travel ban on individuals from Liberia, Sierra Leone, and Guinea, despite the fact that such a ban would be extremely difficult to enforce and would have had a negative economic impact on those countries in the midst of a crisis [80]. In a somewhat ironic display of paranoia, the Louisiana Department of Health and Hospitals, in conjunction with the Governor's Office for Homeland Security and Emergency Preparedness, banned individuals who had traveled to those West African countries from attending the American Society of Tropical Medicine and Hygiene conference in New Orleans [81].

Ultimately, several countries, including the United States, implemented extensive travel screening protocols at airports to detect patients at risk for Ebola and to monitor them for development of disease once they entered the country [82]. The US restricted entry from Ebola-affected countries to five designated airports [83]. Two individuals developed active Ebola infection after arriving by international flight [83, 84]. A third patient, a nurse who contracted the disease while caring for the first Ebola patient in the United States, traveled by domestic airline before she became symptomatic [85]. There were no reported cases of Ebola transmission on any international or domestic flights. It has been postulated that enhanced travel and border health measures helped to curtail the spread of the outbreak [82]. However, an extensive review by the 
Department of Homeland Security Inspector General found several serious deficiencies in the US Ebola screening effort [86].

The WHO International Health Regulations (IHR) (2005) [87] stipulate that the pilot in command of an aircraft is required to inform authorities at destination airports of any health concerns stipulated by "Article 38 Health Part of the Aircraft General Declaration" (unless not required by the destination "State Party") before or at the time of landing. The Declaration requires reporting of passengers or crew who may have a communicable disease, described as a fever (temperature $38^{\circ} \mathrm{C} / 100^{\circ} \mathrm{F}$ or greater) associated with one or more of the following signs or symptoms: appearing obviously unwell; persistent coughing; impaired breathing; persistent diarrhea; persistent vomiting; skin rash; bruising or bleeding without previous injury; or confusion of recent onset, as well as cases of illness disembarked during a previous stop, and information on treatments received during the flight.

The IHR also stipulates that:

The Aircraft shall not be prevented for public health reasons from calling at any point of entry. However, if the point of entry is not equipped for applying health measures, the aircraft may be ordered to proceed at its own risk to the nearest suitable port of entry, unless the aircraft has an operational problem which would jeopardize safety. The aircraft may be restricted to a particular area of the airport with no embarking and disembarking. However, the aircraft shall be permitted to take on, under supervision of the competent authority, fuel, water, food and supplies. [87]

If disembarking is allowed, public health authorities may implement options that range from quarantine, isolation, and treatment, placing suspect persons under health surveillance, to no specific health measures.

\section{US Military Regulations}

The US military services have regulations that govern the transport of infected passengers. One of the most relevant of these regulations for the
AE of potentially contagious patients is USAF Regulation 161-4, which requires aircraft commanders to request an inspection by a quarantine official when an ill passenger has any of the following symptoms and signs: (1) a temperature of $100{ }^{\circ} \mathrm{F}\left(38^{\circ} \mathrm{C}\right)$ or greater accompanied by a rash, lymphadenopathy, or jaundice, or that has persisted for over 48 hours; (2) diarrhea defined as three or more loose stools or a greater than normal amount of loose stool for that person in a 24-hour period; and (3) death due to illness other than physical injuries [88]. The implications of this relatively imprecise and abstruse statement could be considerable. Medical planners must be aware of these regulations because failure to implement their provisions may have international repercussions.

\section{Unanswered Questions}

Certain aspects of our current understanding of the AE of contagious patients remain unresolved. We offer the following questions about issues that may warrant future research:

1. Will additional smoke and simulant dispersal studies be done in various current AE aircraft to determine optimal aircraft type and patient configurations for AE of patients with contagious diseases?

2. Would the use of HEPA-filtered recirculated air reduce the risk of disease transmission in USAF aircraft that could potentially be used for tactical or strategic AE?

3. What is the utility of ultraviolet (UV) light in reducing transmission of airborne infections in aircraft?

4. What is the role of methods such as vaporized hydrogen peroxide in decontaminating aircraft after transport of patients with highly infectious diseases?

5. Should the United States pursue international agreements regarding the entry of military aircraft carrying contagious disease patients into other countries under certain conditions? 
Acknowledgments The opinions and assertions herein are those of the authors and do not purport to reflect official positions of the Department of the Army, Department of the Air Force, or Department of Defense. The authors would like to thank Michael Flueckiger from Phoenix Air for providing information about biological containment systems.

\section{References}

1. Martin TE. Al Jubail-an aeromedical staging facility during the gulf conflict: discussion paper. J R Soc Med. 1992;85(1):32-6.

2. Clayton AJ, O'Connell DC, Gaunt RA, Clarke RE. Study of the microbiological environment within long- and medium-range Canadian Forces aircraft. Aviat Space Environ Med. 1992;47:12.

3. Harper G. The influence of environment on the survival of airborne virus particles in the laboratory. Des archiv fur die virusforschung. 1963;13:64-71.

4. Buckland FE, Tyrrell DAJ. Loss of infectivity on drying various viruses. Nature. 1962;195:2.

5. Hemmes JH, Winkler KC, Kool SM. Virus survival as a seasonal factor in influenza and poliomyelitis. Nature. 1960;188:430-1.

6. Nardell EA. Dodging droplet nuclei: reducing the probability of nosocomial tuberculosis transmission in the aids era. Am Rev Respir Dis. 1990;142(3):501-3.

7. Harding RM. Aviation medicine. 3rd ed. London: BMJ Publishing Group; 1993. p. 120-2.

8. Anonymous. Flight manual, USAF series c-141b aircraft (to tc-141b-t). Washington, DC: US Government Printing Office; 1998.

9. Ewing J. C-17 globemaster iii: Amc's air-lifter of the future. Aerospace Medical Association's 69th Annual Scientific Meeting. Seattle; 1998.

10. Anonymous. Flight manual, USAF series c-130-b, c-130e, and c-130h aircraft (to 1c-130-b-1). Washington, DC: US Government Printing Office; 1996.

11. Jensen PA, Lambert LA, Iademarco MF, Ridzon R. Guidelines for preventing the transmission of mycobacterium tuberculosis in health-care settings, 2005. MMWR. 2005;54(RR-17):1-140.

12. Schulman JL, Kilbourne ED. Airborne transmission of influenza virus infection in mice. Nature. 1962;195(4846):1129-30. https://doi. org/10.1038/1951129a0.

13. Andrews CH, Glover RE. Spread of infection from the respiratory tract of the ferret. I. Transmission of influenza a virus. Br J Exp Pathol. 1941;22:7.

14. Nardell EA, Keegan J, Cheney SA, Etkind SC. Airborne infection: theoretical limits of protection achievable by building ventilation. Am Rev Respir Dis. 1991;144(2):302-6.
15. Harding R. Cabin air quality in aircraft. BMJ. 1994;308(6926):427-8.

16. Driver CR, Valway SE, Morgan W, Onorato IM, Castro KG. Transmission of mycobacterium tuberculosis associated with air travel. JAMA. 1994;272(13):1031-5.

17. Hendley J. Risk of acquiring respiratory tract infections during air travel. JAMA. 1987;258:1.

18. Nagda NGT. Airliner cabin environment: contaminant measurements, health risks, and mitigation options. Washington, DC: US Department of Transportation; 1989.

19. Clayton A. Lassa fever - to air evacuate or not. AGARD-CP. 1975;169:1.

20. Ewington I, Nicol E, Adam M, Cox AT, Green AD. Transferring patients with Ebola by land and air: the british military experience. J R Army Med Corps. 2016;162(3):217.

21. Renemann HH. Transportation by air of a lassa fever patient in 1974. Aeromedical implications of recent experience with communicable disease, agard conference proceedings no 169. Neuilly sur Seine: Advisory Group for Aerospace Research and Development; 1975.

22. Wick RL, Irvine LA. The microbiological composition of airliner cabin air. Aviat Space Environ Med. 1995;66:5.

23. Anonymous. Guide to hygiene and sanitation in aviation. Geneva: World Health Organization; 2009.

24. Klaus J, Gnirs P, Hölterhoff S, Wirtz A, Jeglitza M, Gaber W, et al. Disinfection of aircraft: appropriate disinfectants and standard operating procedures for highly infectious diseases. Bundesgesundheitsblatt Gesundheitsforschung

Gesundheitsschutz. 2016;59(12):1544-8.

25. Ritzinger F. Aeromedical review 4-65 disease transmission by aircraft. Brooks AFB, TX: USAF School of Aerospace Medicine; 1965.

26. Tauxe RV, Tormey MP, Mascola L, Hargrett-Bean NT, Blake PA. Salmonellosis outbreak on transatlantic flights; foodborne illness on aircraft: 1947-1984. Am J Epidemiol. 1987;125(1):150-7.

27. Houk VN, Baker JH, Sorensen K, Kent DC. The epidemiology of tuberculosis infection in a closed environment. Arch Environ Health. 1968;16:10.

28. CDC. Exposure of passengers and flight crew to mycobacterium tuberculosis on commercial aircraft, 1992-1995. MMWR. 1995;44:4.

29. Miller MA, Valway S, Onorato IM. Tuberculosis risk after exposure on airplanes. Tuber Lung Dis. 1996;77(5):414-9.

30. McFarland J, Hickman C, Osterholm M, MacDonald $\mathrm{K}$. Exposure to mycobacterium tuberculosis during air travel. Lancet. 1993;342(8863):112-3.

31. Baxter T. Low infectivity of tuberculosis. Lancet. 1993;342(8867):371.

32. Kenyon TA, Valway SE, Ihle WW, Onorato IM, Castro KG. Transmission of multidrug-resistant mycobacte- 
rium tuberculosis during a long airplane flight. N Engl J Med. 1996;334(15):933-8.

33. Moser MR, Bender TR, Margolis HS, Noble GR, Kendal AP, Ritter DG. An outbreak of influenza aboard a commercial airliner. Am J Epidemiol. 1979;110(1):1-6.

34. Association APH. In: Chin J, editor. Control of communicable diseases manual. Baltimore: United Book Press; 2000.

35. Carrat F, Vergu E, Ferguson NM, Lemaitre M, Nightmare S, Leach S, Valleron AJ. Time lines of infection and disease in human influenza: a review of volunteer challenge studies. Am J Epidemiol. 2008;167(7):775-85.

36. Belser JA, Lash RR, Garg S, Tumpey TM, Maines TR. The eyes have it: influenza virus infection beyond the respiratory tract. Lancet Infect Dis. 2018;18(7):e220-7.

37. CDC. Management of patients with suspected viral hemorrhagic fever. MMWR. 1988;37:16.

38. Slater P. An outbreak of measles associated with a New York/Tel Aviv flight. Travel Med Int. 1995;13:4.

39. Halgelsten JO, Jessen K. Air-transport, a main cause of smallpox epidemics today. Aerosp Med. 1973;44(7):3.

40. Fenner F, Henderson DA, Arita I, Jezek Z, Ladnyi ID. Smallpox and its eradication. Geneva: World Health Organization; 1988.

41. CDC. Smallpox—stockholm. MMWR. 1963;12:3.

42. Garrett L. The coming plague: newly emerging diseases in a world out of balance. New York: Farrar, Straus and Giroux; 1994.

43. Fisher-Hoch SP, Craven RB, Forthall DN, Scott SM, Price ME, Price FM, et al. Safe intensivecare management of a severe case of Lassa fever with simple barrier nursing techniques. Lancet. 1985;326(8466):1227-9.

44. Cooper CB, Gransden WR, Webster M, King M, O’Mahony M, Young S, et al. A case of Lassa fever: experience at St Thomas's Hospital. BMJ (Clin Res Ed). 1982;285(6347):1003-5.

45. Schlaeffer F, Bar-Lavie Y, Sikuler E, Alkan M, Keynan A. Evidence against high contagiousness of Lassa fever. Trans R Soc Trop Med Hyg. 1988;82(2):311.

46. Hotton JM, Bousquet M, Barry B, Lamour O. Aeromedical evacuation of patients with Lassa fever. Aviat Space Environ Med. 1991;62:909-10.

47. WHO. Viral hemorrhagic fevers: report of the WHO expert committee. WHO Tech Rep Ser. 1985;721:5-126.

48. Esler D. The Ebola business. Business and Commerical Aviation. January 2016. https://aviationweek.com/ bca/how-phoenixair-entered-ebola-business.

49. McWhirter C, McKay B. Special Planes Are Lifeline for Ebola Patients. The Wall Street Journal. 2015.

50. Lim MK, Koh D. Sars and occupational health in the air. Occup Environ Med. 2003;60(8):539-40.
51. Olsen SJ, Chang H-L, Cheung TY-Y, Tang AF-Y, Fisk TL, Ooi SP-L, et al. Transmission of the severe acute respiratory syndrome on aircraft. N Engl J Med. 2003;349(25):2416-22.

52. Vogt TM, Guerra MA, Flagg EW, Ksiazek TG, Lowther SA, Arguin PM. Risk of severe acute respiratory syndrome-associated coronavirus transmission aboard commercial aircraft. J Travel Med. 2006;13(5):268-72.

53. Wilder-Smith A, Paton NI, Goh KT. Short communication: low risk of transmission of severe acute respiratory syndrome on airplanes: the Singapore experience. Tropical Med Int Health. 2003;8(11):1035-7.

54. Control CfD. Preventing spread of disease on commercial aircraft: guidance for cabin crew 2017 [cited November 5, 2018]. Available from: https:// www.cdc.gov/quarantine/air/managing-sick-travelers/commercial-aircraft/infection-control-cabincrew.html.

55. Anonymous. Flight manual, USAF series c-130h aircraft (to 1c-130h-1). Washington, DC: US Government Printing Office; 1996.

56. CDC. Update: management of patients with suspected viral hemorrhagic fever-United States. MMWR. 1995;44:5.

57. Hill EE, Mckee KT. Isolation and biocontainment of patients with highly hazardous infectious diseases. J US Army Med Dept. 1991;PB 8-91-1/2:10-4.

58. Wilson KE, Driscoll DM. Mobile high-containment isolation: a unique patient care modality. Am J Infect Control. 1987;15(3):120-4.

59. Christopher GW, Eitzen EM. Air evacuation under high-level biosafety containment: the aeromedical isolation team. Emerg Infect Dis. 1999;5(2):241-6.

60. Clausen LB, Bothwell TH, Isaäcson M, Koornhof HJ, Gear JH, McMurdo J, Payn EM, Miller GB, Sher $\mathrm{R}$. Isolation and handling of patients with dangerous infectious disease. S Afr Med J. 1978;53:6.

61. Clayton A. Containment aircraft transit isolator. Aviat Space Environ Med. 1979;50:6.

62. Trexler PC, Spiers AS, Gaya H. Plastic isolators for treatment of acute leukaemia patients under "germfree" conditions. BMJ. 1975;4(5996):549-52.

63. Trexler PC, Emond RT, Evans B. Negative-pressure plastic isolator for patients with dangerous infections. BMJ. 1977;2(6086):559-61.

64. Withers MR. Aeromedical evacuation of biological warfare casualties: a treatise on infectious diseases on aircraft. Mil Med. 2000;165(11):21.

65. Hutchinson JG, Gray J, Flewett TH, Emond RT, Evans B, Trexler PC. The safety of the Trexler isolator as judged by some physical and biological criteria: a report of experimental work at two centres. J Hyg. 1978;81(2):311-9.

66. Kortepeter MG, Kwon EH, Hewlett AL, Smith PW, Cieslak TJ. Containment care units for managing patients with highly hazardous infectious diseases: a concept whose time has come. J Infect Dis. 2016;214(suppl 3):S137-41. 
67. Esler D. Protection from contagion. Business and Commerical Aviation. January 2016. https://aviationweek.com/bca/protectioncontagion-phoenix-airs-aeromedical-biological-containment-system-gulfstream-iii.

68. Glatter R. The new weapon in the fight against Ebola and other deadly pathogens. Forbes. 2015;13:2015.

69. Morton J. UNMC looks to expand cooperation with pentagon on highly infectious diseases. April 13, 2017.

70. Anonymous. Mobile isolation unit for highly contagious fits air force cargo planes. Stars and Stripes; 2016.; Available from: https://www.stripes.com/news/ mobile-isolation-unit-for-highly-contagious-fits-airforce-cargo-planes-1.399701.

71. Anonymous. Human systems center (brooks afb, tex), products and progress. Available from: http://www. brooks.af.mil/hsc/ya/yac/aerp.htm.

72. Anonymous. Flight manual, USAF series c-9a aircraft (to 1c9-a-1). Washington, DC: US Government Printing Office; 1997.

73. Zachary Cacicia. New aircrew masks tested at dover 2016: Available from: http://www.amc. af.mil/News/Article-Display/Article/785873/ new-aircrew-masks-tested-at-dover/.

74. Merwin CA. U.S. Air Force patient airlift: from balloons to high-speed jets. J Air Med Transp. 1990;9(1):18-22.

75. Coates J. Internal medicine in world war ii. Vol ii. Infectious diseases. Washington, DC: Office of the Surgeon General, Department of the Army; 1963.

76. Reed K. Draft of united states air force concept of operations (conops) for management of biological warfare casualties (unpublished 2nd draft); 1997.

77. Perin M. Transportation in commercial aircraft of passengers having contagious diseases. Aviat Space Environ Med. 1976;47:5.

78. Wills C. Yellow fever, black goddess: the co-evolution of people and plagues. Reading: Helix Books, Addison-Wesley Publishing Co; 1996.
79. CDC. Detection of notifiable diseases through surveillance for imported plague-New York, SeptemberOctober 1994. MMWR. 1994;43:3.

80. Dastin J. U.S. Airlines point to additional problems of any Ebola travel ban. Reuters; 2014. Available from: http://www.reuters.com/article/us-health-ebola-usaairlines/u-s-airlines-point-to-additional-problems-ofany-ebola-travel-ban-idUSKBNOIH2CT20141028.

81. Asgary R, Pavlin JA, Ripp JA, Reithinger R, Polyak $\mathrm{CS}$. Ebola policies that hinder epidemic response by limiting scientific discourse. Am J Trop Med Hyg. 2015;92(2):240-1.

82. Cohen N. Travel and border health measures to prevent the international spread of Ebola. MMWR Suppl. 2016;65(3):11.

83. CDC. Enhanced Ebola screening to start at five U.S. airports and new tracking program for all people entering U.S. from Ebola-affected countries; 2014.

84. Botelho GW, Wilson J. Thomas Eric Duncan: first Ebola death in the U.S.: CNN; 2014. Available from: http://www.cnn.com/2014/10/08/health/thomas-ericduncan-ebola/index.html.

85. News A. Nurse who contracted Ebola called CDC before flight, official says; 2014.

86. Department of Homeland Security, Office of Inspector General, Report No. OIG-16-18. Ebola response needs better coordination, training and execution; January 6, 2016 [cited November 14, 2018]. Available from: https://www.oig.dhs.gov/assets/Mgmt/2016/ OIG-16-18-Jan16.pdf.

87. Anonymous. In: WHO, editor. International health regulations. 3rd ed. Geneva, Switzerland: World Health Organization Press; 2005.

88. USAF. Quarantine regulations of the armed forces. Departments of the navy, army, and the air force. Washington, DC: US Government Printing Office; 1992. 